\section{Is it not time to reveal the secret sauce of nicotine addiction?}

\author{
K Michael Cummings
}

In the courtroom, cigarette companies like to paint a picture that their consumers are informed about the health risks of their products so that they can argue that smokers are fully responsible for any health consequences that might arise. ${ }^{1}$ While that is a convenient legal defense, it is a smoke screen. The reality is most consumers have not got a clue how their cigarettes are engineered and how the design of their cigarettes might relate to why they find it hard to stop smoking and why they get sick as a result. ${ }^{2}$ While I have heard

Correspondence to K Michael Cummings, PhD, MPH, Department of Psychiatry \& Behavioural Sciences, Medical University of South Carolina, 68 President Street, BEB 103-L, Charleston, SC 29425, USA; cummingk@musc.edu defense lawyers argue that consumers really are not interested in knowing how their cigarettes are made, that argument is contradicted by polling data showing that the vast majority of smokers want to know more about the products they use. ${ }^{2}$

While some governments have succeeded in requiring tobacco manufacturers to disclose information about their products, most of the data obtained has been useless to consumers, because it cannot be shared on the grounds that the design specifications are trade secrets. The paper by Velicer $e t a l^{3}$ is important since it reveals that the trade secret argument used by manufacturers to keep consumers in the dark about how their products are engineered is baseless-because their own business records show that companies have for decades routinely analysed their competitors' cigarettes in great detail. Thus, the information is neither secret nor commercially valuable, and thus does not meet the legal definition of a 'trade secret'.

So why have cigarette manufacturers fought so hard to keep their historical brand formulas a secret? The answer can be found in the internal business records of the cigarette companies. ${ }^{4} 5$ In 1963, the chief lawyer for Brown \& Williamson wrote- "we are in the business of selling nicotine, an addictive drug". 6 In a related business record written in the same year, the head scientist at Brown \& Williamson observed: "the nicotine levels of $B \& W$ cigarettes were not obtained by accident... we can regulate fairly precisely the nicotine and sugar levels to almost any desired level management might require". A 1972 RJ Reynolds Tobacco Company research and Development document observed that the company should "recognise the key role of nicotine in consumer satisfaction and promote our product with this in mind". 8 A similar focus can be found in a 1977 Philip Morris internal 
business record which said that research into human smoking behaviour was performed to "increase corporate profits... and without the chemical compound (ie, nicotine) the cigarette market would collapse, PM would collapse, and we'd all lose our jobs and our consulting fees". No doubt consumers would be shocked to learn how cigarettes have been engineered with man-made tobaccos laced with ammonia, additives and other ingredients that changed frequently over time without notification and with little regard given to downstream health consequences (human experimentation without consent). ${ }^{4}{ }^{5}$ However, another reason for keeping historical brand formulas secret can be found in a 1980 internal business record which revealed that inside the cigarette industry, lawyers warned that "the entire matter of addiction is the most potent weapon a prosecuting attorney can have in a lung cancer/cigarette case. We can't defend continued smoking as free choice if the person was addicted". ${ }^{10}$

The scientific consensus today is that nicotine addiction is the fundamental reason that people persist in smoking, which in turn results in one in two longterm cigarette smokers dying prematurely from smoking-related diseases. ${ }^{11}$ Were it not for designing products that induce and maintain nicotine addiction, we would not have a tobacco and health problem. ${ }^{11}$ Given the emerging consensus that cigarettes have become even more dangerous and perhaps even more addictive over time (ie, the relative risks for smoking and multiple diseases have increased) there is an urgency to know why. ${ }^{12}{ }^{13}$ Changes in product designs would seem to be a logical explanation, but without knowing precisely how different brands and subbrands have been engineered and modified, it is impossible to know for sure. ${ }^{12} 13$
One would never undertake a study to evaluate the health impact of a drug without knowing the precise specifications of the drug and ensuring its uniformity over the course of the study. Yet, that is precisely the problem that has confronted those evaluating the disease effects of cigarette smoking. Velicer $e t a l^{3}$ are absolutely correct in pointing out the insanity of hiding behind trade secrets as an excuse not to release historical brand formulas.

Consumers and regulators have been kept in the dark for too long. Consumers cannot make informed product choices if product information is concealed; scientists cannot accurately assess the risks of a product if the product is being modified without their knowledge, and regulators like the Food and Drug Administration (FDA) cannot regulate a moving target. It is long since time to put the interests of consumers before those of cigarette manufacturers and require them to publicly disclose historical by-brand formulas and design specifications.

Competing interests KMC has received payment as an expert witness in litigation filed against the tobacco industry.

Provenance and peer review Commissioned; internally peer reviewed.

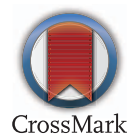

To cite Cummings KM. Tob Control 2015;24:420421

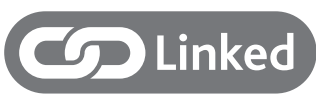

- http://dx.doi.org/10.1136/tobaccocontrol-2014051571

Tob Control 2015;24:420-421.

doi:10.1136/tobaccocontrol-2015-052631

\section{REFERENCES}

1 Friedman LC, Cheyne A, Givelber D, et al. Industry use of personal responsibility rhetoric in public relations and litigation: disguising freedom to blame as freedom of choice. Am J Public Health 2015;105:250-60.

2 Cummings KM, Hyland A, Giovino GA, et al. Are smokers adequately informed about the health risks of smoking and medicinal nicotine? Nicotine Tob Res 2004;6(Suppl 3):333-40.

3 Velicer C, Lampert L, Glantz S. Cigarette company trade secrets are not secret: an analysis of reverse engineering reports in internal tobacco industry documents released as a result of litigation. Tob Control 2015;24:469-80.

4 Stevenson T, Proctor RN. The secret and soul of Marlboro: Phillip Morris and the origins, spread, and denial of nicotine freebasing. Am I Public Health 2008:98:1184-94.

5 Hurt RD, Robertson CR. Prying open the door to the tobacco industry's secrets about nicotine: the Minnesota Tobacco Trial. JAMA 1998;280:1173-81.

6 Yeaman A. Implications of Battelle Hippo I \& II and the Griffith Filter. Brown and Williamson Tobacco Company. 1963, Bates: 2046754905-2046754909.

7 Griffth RB. Letter to John Kirwan at British-American Tobacco Company. Brown \& Williamson Tobacco Company. 1963. Bates: 102630333-102630336.

8 Teague CE. Research planning memorandum on the nature of the tobacco business and the crucial role of nicotine therein. R.J. Reynolds Tobacco Company. 1972. Bates: 500915683-500915691.

9 Dunn W. Smoker psychology program review. Philip Morris Tobacco Company. 1977. Bates: 1000046538-1000046546.

10 Knopick P. Memo to William Kloepfer. Tobacco Institute. 1980. Bates: 1000135335-1000135336.

11 U.S. Department of Health and Human Services. How tobacco smoke causes disease: the biology and behavioral basis for smoking-attributable disease: a report of the surgeon general. Atlanta, GA: U.S. Department of Health and Human Services, Centers for Disease Control and Prevention, National Center for Chronic Disease Prevention and Health Promotion, Office on Smoking and Health, 2010.

12 Thun MJ, Carter BD, Feskanich D, et al. 50-year trends in smoking-related mortality in the United States. N Engl I Med 2013;368:351-64.

13 U.S. Department of Health and Human Services. The health consequences of smoking - 50 years of progress: a report of the surgeon general. Atlanta, GA: U.S. Department of Health and Human Services, Centers for Disease Control and Prevention, National Center for Chronic Disease Prevention and Health Promotion, Office on Smoking and Health, 2014. 